\title{
Investigations on the Modifications in Ignition Delay Time of Shellac-based Pyrotechnic Igniter using Additives of Varying Particle Size
}

\author{
Lakshay Bansal $^{1}$, Prakhar Jindal ${ }^{1}$, Manish Kumar Bharti ${ }^{1, *}$
}

\author{
Bansal L (D) https: / / orcid. org/0000-0001-9613-7770 \\ Jindal P (10 https: / / orcid.org/0000-0002-5341-7809 \\ Bharti MK 미 https:/ / orcid.org/0000-0002-2307-7938
}

\section{How to cite}

Bansal L, Jindal P, Bharti MK (2020) Investigations on the Modifications in Ignition Delay Time of Shellac-based Pyrotechnic Igniter using Additives of Varying Particle Size. J Aerosp Tecnol Manag, 12 e3820. https://doi.org/10.5028/jatm. v12.1178

\begin{abstract}
Modifications achieved in the ignition delay time of shellac-based pyrotechnic igniter using different additives of varying particle size are observed and compared. 40 different pyrotechnic compositions were prepared using five additives i.e. aluminium, magnesium, red iron oxide, naphthalene and activated carbon. Four particle sizes i.e. $<75 \mu \mathrm{m}, 75-150 \mu \mathrm{m}$, 150-300 $\mu \mathrm{m}, 300-600 \mu \mathrm{m}$ and two weight percentages of the additives i.e. $3 \%$ and $5 \%$ were investigated. A base composition, without any additive, was also prepared to compare and investigate the effects of additives and their particle size on the ignition delay time of the composition. The incorporation of additives significantly reduced the ignition delay time of the base composition. Addition of $5 \%$ red iron oxide having a particle size of $<75 \mu \mathrm{m}$, delivered the maximum decrement in ignition delay time i.e. by 49.7\%. Naphthalene of particle size of $<75 \mu \mathrm{m}$ added as $3 \%$ in the composition weight, provided the minimum reduction in the ignition delay time i.e. by $13.7 \%$. It was also observed that all of the additives exhibited a similar manner of decrement in ignition delay time as the particle size decreased, except for naphthalene which exhibited an opposite trend.
\end{abstract}

KEYWORDS: Pyrotechnic Igniter; Ignition delay time; Shellac igniter; Potassium nitrate; Particle size.

\section{INTRODUCTION}

Composite Solid Propellant (CSP) rockets require an ignition device, called a pyrotechnic igniter, to initiate the burning process of the propellant grain. Electrical, mechanical, chemical, shock-induced, laser or the combinations of these methods are used as the energy input sources to start the ignition process. The energy input is converted into heat energy output which is transferred to the propellant surface (Kulkarni et al. 1982; Sivan and Hass 2015). Pyrotechnic igniter, which is a device containing a pyrotechnic composition in a small volume, is used to initiate combustion of materials that are comparatively difficult to ignite. A simple pyrotechnic igniter is generally controlled electrically, using a heated bridge-wire or a wire resistor (Klingenberg 1984). The electro-explosive device is the most used type of the pyrotechnic igniter that uses a nichrome or tungsten wire placed between the terminals of an electric source. An electric charge is used to start the ignition by providing the required heat energy for the chemical reaction to take place (Danali et al. 2010). The ignition delay time is defined as the time interval between when the signal is received for initialization of the heat source and when the first bit of the grain burns. This time delay comprises the

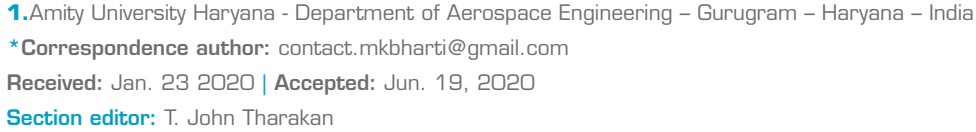


time required for the heat from the source to convert the solid charge into the vapour phase and to reach the flashpoint of the charge. The overall ignition delay time $\left(t_{I D}\right)$ is usually the summation of pyrolysis time $\left(t_{p}\right)$, mixing time $\left(t_{m}\right)$ and a gas phase chemical reaction time $\left(t_{c}\right)$. Generally, the $t_{m}$ and $t_{c}$ are observed to be overlapping, are very small in magnitude and thus neglected. Consequently, the overall ignition delay time of any given pyrotechnic composition represents the time being consumed in the production of pyrolysis products containing the gaseous charge. (Aswin et al. 2012; Li et al. 2018). Extended research to observe the contribution of individual components in the overall ignition delay time of given composition can be calculated using Eq. 1 to Eq. 4 but are presently beyond the scope of this study. Therefore, the ignition delay time of various compositions that are reported here can be summarised as the pyrolysis time of any given composition. Mathematically:

$$
\begin{gathered}
t_{I D}=t_{p}+t_{m}+t_{c} \\
\text { where, } t_{p}=\frac{\pi p_{s} c_{p}\left(T_{s}-T_{\infty}\right)^{2}}{4_{\mathrm{Q} 0}^{2}} \\
t_{m}=\frac{k^{2}}{h_{C}^{2} D} \text {, and } \\
t_{c}=\frac{C k T_{\infty}}{\alpha\left[\frac{E}{R T_{\infty}}\right] \Delta h_{c} A e^{\left[\frac{E}{R T_{\infty}}\right]}}
\end{gathered}
$$

where $p_{S}$ is the solid propellant density, $c_{P}$ is the specific heat, $k$ is thermal conductivity, $Q_{0}$ is heat flux density, $T_{S}$ is propellant surface temperature and $T_{\infty}$ is the ambient temperature (Tewarson 2002). Also, $h_{C}$ is convective heat transfer coefficient, $D$ is diffusion coefficient, $\alpha$ is the thermal diffusion coefficient, $E$ is the activation energy, $R$ is gas constant, $\Delta h_{c}$ is the heat of combustion, $A$ is a pre-exponential factor and $C$ is constant-coefficient (Quintiere 2006).

Shellac is a large hydrocarbon group and a natural binder with low ignition delay time and ignition temperature (Sharma et al. 1983). The use of shellac as a potential binder in the pyrotechnic compositions have attracted the interest of researchers as early as the end of the $19^{\text {th }}$ century. Shellac dissolved in alcohol has been used as a binder along with potassium chlorate, sulphur and carbon black to make the ignition fuse of the pyrotechnic devices (Hunt 1879). Shellac along with aluminium (Al) and barium peroxide has been used in the explosive charge of ignition pallet for a thermally controlled rocket (Balcarczyk 1973). A comparative study between $\mathrm{Al}$ particles and shellac-coated $\mathrm{Al}$ particles has been conducted using Thermogravimetric (TG) and Differential Scanning Calorimetry (DSC) techniques. It was found that shellac-coated $\mathrm{Al}$ particles had a protective effect on $\mathrm{Al}$ particles when stored for 8 months. The oxidation temperature for shellac-coated $\mathrm{Al}$ particles was found to be less as compared to that of uncoated Al particles (Mingquan et al. 2016). Such properties along with high heat output and exothermicity, encourage to explore the potential of shellac to be used as a fuel/binder in pyrotechnic compositions (Singh et al. 1988; Barisin and Batinic-Haberle 1994).

Zirconium potassium perchlorate (ZPP), boron potassium nitrate (BPN) and titanium hydride potassium perchlorate (THPH) are the most used compositions for the commercial pyrotechnic igniters. A composition containing $52 \%$ zirconium, $42 \%$ potassium perchlorate, $1 \%$ graphite and $5 \%$ viton B is used as NASA's standard igniter (Hohmann et al. 2000).

Ignition delay time for boron-potassium nitrate $\left(\mathrm{B}-\mathrm{KNO}_{3}\right)$ based igniter, when measured under a closed vessel is found to be 60 milliseconds. The value for ignition delay time varied as the amount and the type of binder used were changed (Bhingarkar and Singh 2006). In another study, $50 \mathrm{mg}$ samples of gunpowder with $10 \%$ sulphur, shellac-based $\mathrm{B}-\mathrm{KNO}_{3}$ and acaroid resin-based magnesium-potassium nitrate $\left(\mathrm{Mg}-\mathrm{KNO}_{3}\right)$ composition has been tested for ignition delay time using an argon ion laser. It was found that ignition delay time for gunpowder was 1.15 seconds with the flux density of $30 \mathrm{~W} / \mathrm{cm}^{2}$, for shellac-based B- $\mathrm{KNO}_{3}$ the 


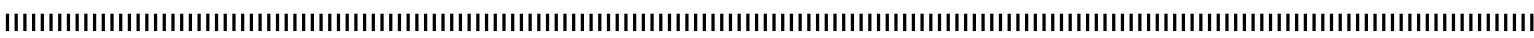

ignition delay time was found to be $\sim 0.56$ seconds with a flux density of $55 \mathrm{~W} / \mathrm{cm}^{2}$ and for Acaroid resin-based $\mathrm{Mg}^{-} \mathrm{KNO}$ it was 0.6 seconds at a flux density of $63 \mathrm{~W} / \mathrm{cm}^{2}$ (Ahmad and Russell 2005).

Precise environmental conditions are essential for a successful launch which might get altered because of the occurrence of significant delay in the launch time. That is why the ignition delay time of the igniter needs to be known so that the electrical signal can be engaged at the exact moment. This would facilitate proper and swift ignition of the igniter composition, thereby reducing the chances of the delayed rocket launch. Also, to successfully disengage the external heat source, the exact moment when the composition becomes self-sustained in terms of combustion is needed to be known. Undesired combustion of the main propellant may occur because of the over-engagement of the external heat source, significantly affecting the combustion and ballistic parameters.

The contemporary pyrotechnic igniters used by global space organizations are generally expensive due to their complex ingredients. Shellac based pyrotechnic igniters are comparatively inexpensive and their calorific value can be enhanced by the incorporation of different additives. The various aforementioned features of shellac as the potential candidate for use as the binder/fuel are the motivation behind the present study. The present study aims to investigate the effects and modifications achieved in the ignition delay time of shellac-based pyrotechnic igniter through the incorporation of different additives having different particle sizes.

\section{EXPERIMENT}

\section{MATERIALS}

Potassium Nitrate (make- $\mathrm{CDH}$, purity $>99.5 \%$ ), shellac flakes (make- CDH, purity >98.99\%), naphthalene (make- $\mathrm{CDH}$, purity $>99 \%$ ), activated carbon (make- Qualikems, purity $>99.38 \%$ ), aluminium powder (make- Qualikems, purity $>99.97 \%$ ), red iron oxide (make- Qualikems, purity $>98.5 \%$ ), magnesium powder (make- Qualikems, purity >98\%), and isopropyl alcohol (make- Quali-techs, purity $>99 \%$ ) were commercially obtained for the study. Table 1 summarises the various fundamental physical and chemical properties of the different ingredients.

Table 1. Chemical and physical properties of the ingredients.

\begin{tabular}{|c|c|c|c|c|c|}
\hline Ingredient & Phase at NTP & $\begin{array}{l}\text { Chemical } \\
\text { Formula }\end{array}$ & $\begin{array}{l}\text { Molar Mass } \\
{[\mathrm{g} / \mathrm{mol}]}\end{array}$ & $\begin{array}{l}\text { Density } \\
{\left[\mathrm{g} / \mathrm{cm}^{3}\right]}\end{array}$ & $\begin{array}{l}\text { Melting Point } \\
\quad\left[{ }^{\circ} \mathrm{C}\right]\end{array}$ \\
\hline Shellac & Solid & $\mathrm{C}_{30} \mathrm{H}_{50} \mathrm{O}_{11}$ & 586.71 & 1.14 & 82 \\
\hline Potassium nitrate & Solid & $\mathrm{KNO}_{3}$ & 101.10 & 2.11 & 334 \\
\hline Isopropyl alcohol & Liquid & $\mathrm{C}_{3} \mathrm{H}_{7} \mathrm{OH}$ & 60.10 & 0.79 & -89 \\
\hline Aluminium & Solid & $\mathrm{Al}$ & 26.98 & 2.70 & 660.3 \\
\hline Magnesium & Solid & $\mathrm{Mg}$ & 24.30 & 1.73 & 650 \\
\hline Red iron oxide & Solid & $\mathrm{Fe}_{2} \mathrm{O}_{3}$ & 159.69 & 5.24 & 1565 \\
\hline Naphthalene & Solid & $\mathrm{C}_{10} \mathrm{H}_{8}$ & 128.17 & 1.14 & 80.26 \\
\hline Activated carbon & Solid & $\mathrm{C}$ & 12.011 & 0.65 & - \\
\hline
\end{tabular}

The various ingredients and their respective weight percentages (wt.\%) used to prepare the pyrotechnic stars for the investigation are presented in Table 2. Shellac is a polar substance and thus an organic polar solvent was used to dissolve and to activate its binding property (Sharma et al. 1983). Fuel (shellac) and oxidizer (potassium nitrate, $\mathrm{KNO}_{3}$ ) were mixed in a wt.\% ratio of $1: 4$ for the base composition. The oxidizer's wt.\% was kept constant in all of the compositions to ensure that a sufficient amount of oxygen is available for the combustion of shellac and additives. The wt.\% for the additives in the composition was kept as $3 \%$ and $5 \%$. The wt.\% of the additives beyond 5\% would have subsequently reduced the amount of shellac in the composition and thus had been avoided since this reduction would have made a negative impact on the binding properties of the composition. The additives used were aluminium, magnesium, red iron oxide, naphthalene, and activated carbon. 
Table 2. Constituents and their wt.\% in the composition.

\begin{tabular}{|c|c|c|c|c|}
\hline \multirow{2}{*}{ Composition } & \multicolumn{3}{|c|}{ Wt.\% in the composition [\%] } & \multirow{2}{*}{$\begin{array}{c}\text { For every } 10 \mathrm{~g} \text { of the composition } \\
\text { Solvent }[\mathrm{g}]\end{array}$} \\
\hline & Fuel & Additive & Oxidizer & \\
\hline Base Composition & 20 & 0 & 80 & 2.0 \\
\hline Composition A & 17 & 3 & 80 & 1.7 \\
\hline Composition B & 15 & 5 & 80 & 1.5 \\
\hline
\end{tabular}

\section{PREPARATION OF PYROTECHNIC STARS}

Woven wire mesh sieves conforming to ASTM E11-16 and ISO 3310-1 standards were used to segregate all of the five additives into different particle size groups i.e. $<75 \mu \mathrm{m}, 75-150 \mu \mathrm{m}, 150-300 \mu \mathrm{m}$, and 300-600 $\mu \mathrm{m}$. Shellac flakes were first grinded using mortar and pestle, and then an electric grinder was used to obtain a powder which was then sieved to obtain the fine shellac powder of particle size between $75-150 \mu \mathrm{m}$. The same fine shellac powder was used in preparing all the compositions. Isopropyl alcohol was used as the organic polar solvent to completely dissolve the shellac powder. In the prepared compositions, the additives were added at the expense of shellac's weight percentage. The amount of Isopropyl alcohol added in the composition was not considered as a part of the total composition's weight because of its volatile nature. Many trials were performed with different quantities of the solvent and it was found that minimum solvent quantity required to effectively activate the binding property of shellac was $10 \%$ of the amount of shellac in the composition.

Ingredients were added in a $50 \mathrm{~mL}$ glass beaker in small instalments and were mixed thoroughly using a clean glass rod. The composition slurry was then hand-casted into multiple spherical beads of comparable shape and weight. Each bead was $1.5 \mathrm{~cm} \pm 0.1 \mathrm{~cm}$ in diameter and $2 \mathrm{~g} \pm 0.01 \mathrm{~g}$ in weight to ensure uniformity in density. Given the imposed dimensional, weight, particle size and volumetric constraints on the prepared pyrotechnic beads, it can be safely assumed that the porosity among the samples belonging to different categories must also be the same. Figure 1 depicts the prepared pyrotechnic stars with Red Iron oxide, activated carbon, magnesium, aluminium and naphthalene as additives. Four pyrotechnic stars were prepared for each composition to get an average value of the ignition delay time of the composition. The prepared pyrotechnic stars were kept in a desiccator for 24 hours to remove any traces of moisture.

(a)

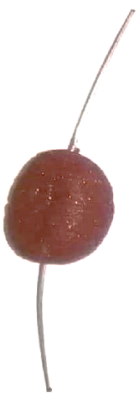

(b)

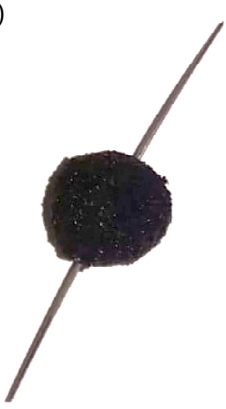

(c)

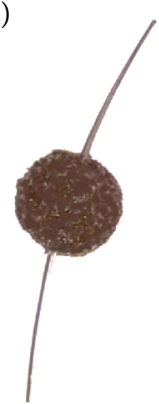

(d)

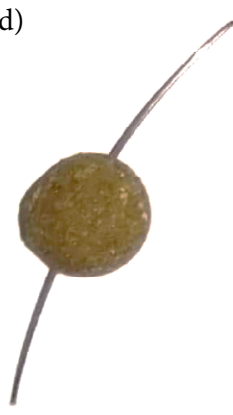

(e)

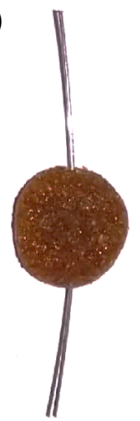

Figure 1. Pyrotechnic star with (a) Red iron oxide, (b) Activated carbon (c) Magnesium (d) Aluminium and (e) Naphthalene. 


\section{EXPERIMENTAL SETUP}

Nichrome wire having a diameter of $0.62 \mathrm{~mm}$ and a length of $6 \mathrm{~cm}$ was pierced through the centre of the pyrotechnic stars (as represented in Fig. 1) to ensure that similar amount of grain is available on all sides for proper combustion. A hand-held electrical ignition system was fabricated to conduct the investigation. Figure 2 represents the line diagram of the electrical setup and circuitry of the fabricated ignition system. The ignition system was powered with the help of a $12 \mathrm{~V}, 7 \mathrm{Ah}$ battery and alligator clips were used to hold the pyrotechnic stars between the terminals of the battery.

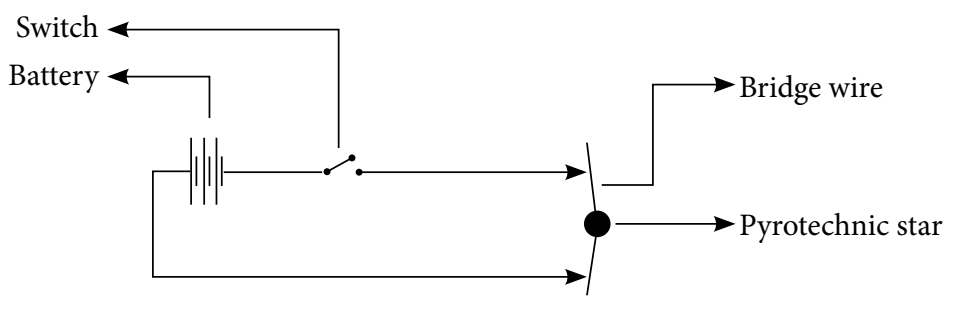

Figure 2. Line diagram of the electrical ignition system.

\section{IGNITION DELAY TIME TEST}

Investigations for the ignition delay time were carried out in a fume hood to ensure proper ventilation and to eliminate any chances of exposure to combustion gases. Four pyrotechnic stars from each composition having different additive and different particle size were thus tested and video recorded at $60 \mathrm{fps}$ (frames per second) using a high definition digital camera. The video recordings of the ignition process of the pyrotechnic stars were later viewed at 0.5 times the playback speed and the ignition delay time for each composition was obtained by calculating the time lag between the activation of the ignition system mark and the occurrence of first visible spark. The smokestack of the fume hood was turned on every time before the subsequent testing to facilitate a clean environment. The battery was checked using a digital multimeter to ensure that the $7 \pm 0.02 \mathrm{~A}$ of current was available each time before a pyrotechnic star was attached in between the battery terminals for testing.

\section{RESULTS AND DISCUSSION}

Additives were incorporated for enhancement of combustion parameters. Ignition of additive resulted in a quicker ignition of the pyrotechnic star as it brought a significant alteration in burn rate as well as the overall fuel's particle surface temperature facilitating the reduction in ignition delay time. The dependence of ignition delay time on the particle size of the additives was since the ignition of larger particle size required a large amount of heat from the heat source when compared to the particles with the smaller size as the latter one had more surface area in contact with the heat source directly. The average ignition delay time for the base composition was found to be 1.43 seconds. Table 3 presents the average ignition delay time (rounded to the nearest hundredths) obtained for various prepared pyrotechnic compositions along with the standard deviation (rounded to the nearest ten-thousandths) amongst four pyrotechnic stars of each composition. The maximum and minimum standard deviation in ignition delay time for pyrotechnic stars with $3 \%$ additive's wt. $\%$ was observed to be as 0.0275 and 0.0082 , respectively. In pyrotechnic stars having $5 \%$ of additive wt.\%, the maximum and minimum standard deviation in ignition delay time was observed to be as 0.0311 and 0.0096 , respectively.

It is observed from Table 3 that all of the compositions having $5 \%$ additive in the composition provided reduced ignition delay times as compared to compositions having $3 \%$ additive but except for naphthalene. This observed phenomenon can be attributed to the fact that as the quantity of additive in the composition was increased, it resulted in a decrease in the amount of binder (shellac) available in the composition that eventually led to an increase in the flame temperature. In the case of metallic additives i.e. aluminium, magnesium and red iron oxide, the energy released from metallic combustion was much higher as compared to that of the energy released from the combustion of an organic binder. In the case of activated carbon, the increase in the additives wt.\% resulted in the presence of extra fused oxygen in the composition. Both of these characteristics led to an increase in the 
flame temperature of the compositions. Such increment in the composition's flame temperature provided more heat energy to the unburnt grain for enhanced rate and decreased time of pyrolysis of the composition (Bhingarkar and Singh 2006).

The samples with more fuel tightly packed in a given volume as compared to that of a sample with comparatively less fuel required more heat energy for the combustion process to be initiated. In case of shellac as the fuel, the heat energy supplied to the composition from the ignition source was partly getting used in breaking the bonds between aromatic and carbon groups present in shellac. In pyrotechnic stars with additives as 3\% of the composition's weight, the amount of the shellac was higher as compared to the amount of shellac in the pyrotechnic stars with additives incorporated as $5 \%$ of the composition's weight.

Table 3. Average ignition delay time in pyrotechnic stars

\begin{tabular}{|c|c|c|c|c|}
\hline \multirow[b]{2}{*}{ Particle size $(\mu \mathrm{m}]$} & \multicolumn{2}{|c|}{ 3\% Additive [wt.\%] } & \multicolumn{2}{|c|}{ 5\% Additive [wt. \%] } \\
\hline & $\begin{array}{l}\text { Average Ignition } \\
\text { Delay Time [s] }\end{array}$ & Standard Deviation & $\begin{array}{l}\text { Average Ignition } \\
\text { Delay Time [s] }\end{array}$ & Standard Deviation \\
\hline \multicolumn{5}{|c|}{ Aluminium } \\
\hline$<75$ & 0.93 & 0.0082 & 0.89 & 0.0126 \\
\hline $75-150$ & 0.97 & 0.0129 & 0.92 & 0.0096 \\
\hline $150-300$ & 1.06 & 0.0126 & 0.96 & 0.0265 \\
\hline $300-600$ & 1.11 & 0.0134 & 0.99 & 0.0113 \\
\hline \multicolumn{5}{|c|}{ Magnesium } \\
\hline$<75$ & 0.81 & 0.0082 & 0.78 & 0.0126 \\
\hline $75-150$ & 0.89 & 0.0126 & 0.91 & 0.0275 \\
\hline $150-300$ & 1.00 & 0.0275 & 0.98 & 0.0263 \\
\hline $300-600$ & 1.10 & 0.0263 & 1.05 & 0.0150 \\
\hline \multicolumn{5}{|c|}{ Red iron oxide } \\
\hline$<75$ & 0.75 & 0.0082 & 0.72 & 0.0171 \\
\hline $75-150$ & 0.81 & 0.0171 & 0.78 & 0.0275 \\
\hline $150-300$ & 0.86 & 0.0082 & 0.83 & 0.0191 \\
\hline $300-600$ & 0.96 & 0.0082 & 0.91 & 0.0238 \\
\hline \multicolumn{5}{|c|}{ Naphthalene } \\
\hline$<75$ & 1.23 & 0.0096 & 1.22 & 0.0222 \\
\hline $75-150$ & 1.13 & 0.0171 & 1.12 & 0.0216 \\
\hline $150-300$ & 1.00 & 0.0275 & 0.99 & 0.0189 \\
\hline $300-600$ & 0.93 & 0.0096 & 0.94 & 0.0163 \\
\hline \multicolumn{5}{|c|}{ Activated carbon } \\
\hline$<75$ & 0.88 & 0.0141 & 0.84 & 0.0096 \\
\hline $75-150$ & 0.93 & 0.0096 & 0.89 & 0.0206 \\
\hline $150-300$ & 0.98 & 0.0183 & 0.95 & 0.0129 \\
\hline $300-600$ & 1.10 & 0.0236 & 1.06 & 0.0311 \\
\hline
\end{tabular}


Figures $3 \mathrm{a}$ and $3 \mathrm{~b}$ represent the comparative graphs and trends of calculated average ignition delay times of pyrotechnic stars having different additives of different particle size for 3\% and 5\% of additive's wt.\% in the composition, respectively. The composition with red iron oxide was observed to have the least ignition delay time as compared to the rest of the compositions. This can be attributed to the phenomenon reported in the literature that the red iron oxide is an oxygen carrier (Chakravarthy et al. 1997; Mattisson et al. 1953). The high heat output of shellac increased the rate of reduction which facilitated the catalytic action in the reaction. Due to this catalytic behaviour, pyrotechnic stars with red iron oxide as an additive exhibited reduced ignition delay times. Also, studies conducted on different carbon fuel with red iron oxide as fuel had indicated that its addition increases the combustion rate by facilitating a complete oxidation reaction (Gong et al. 2010; Devener and Anderson 2006).
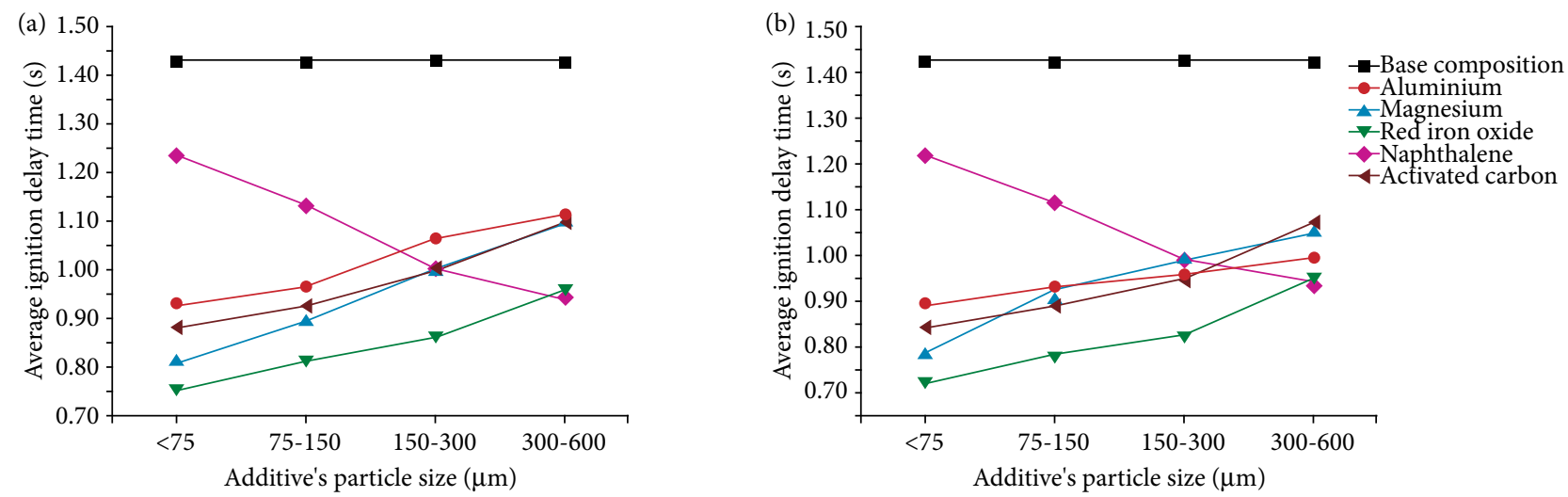

Figure 3. Average ignition delay times with additive's wt.\% as; (a) 3\%, and (b) 5\%.

Magnesium is reported to even react in an atmosphere with abundant carbon dioxide $\left(\mathrm{CO}_{2}\right)$ and carbon monoxide (CO) gases (Shafirovich and Goldshleger 1991). The quantity of available oxidizer thereby increased as the decomposition reaction of hydrocarbon fuel i.e. shellac in the presence of an oxidizer produced a large quantity of $\mathrm{CO}_{2}$ gas. Thus, for the compositions with magnesium as an additive, there was more than one oxidizer available for contributing to the combustion reaction i.e. $\mathrm{KNO}_{3}$ and $\mathrm{CO}_{2}$.

Since the melting point of the aluminium oxide is lower than that of the boiling point of the pure aluminium, there existed a recurring process of formation and melting of the oxide layer present at the surface of the aluminium particles (Glotov and Surodin 2019). This repetitive process absorbed a significant portion of the heat available for the vaporization of the propellant grain resulting in higher ignition delay times compared to that of magnesium-based compositions. Magnesium is reported to ignite explosively as the boiling point of pure magnesium is lower than the melting point of magnesium oxide (Feng and Xia 2019). The pure magnesium metal, enclosed inside the protective oxide layers, boiled off and the pressure inside the oxide layer built up eventually leading to the aggressive rupture of the oxide layer. These continuous rupturing events extensively transferred the heat to the propellant grain resulting in rapid vaporization of the charge, subsequently leading to the reduced ignition delay times for the magnesium-based pyrotechnic stars.

Naphthalene was selected as an additive for the present study to observe and compare the effects of a hydrocarbon additive with that of metallic and inorganic additives. Interestingly, a reversed pattern was observed for the modifications achieved in ignition delay times when naphthalene was incorporated as an additive. Such an opposite trend was observed because naphthalene is a compound having a large group of aromatic hydrocarbons. It is reported that upon combustion of naphthalene, the initial result is the formation of fullerene and final products are numerous polycyclic aromatic hydrocarbons (Garcia et al. 2006). This leads to the opinion that initially the bonds between carbons needed to be broken followed by the dissociation of carbon-hydrogen bonds. As the particle size increased, the distance between the carbon and hydrogen atom increased, decreasing the strength of the bond. Less external heat energy was thus required to start the ignition of the pyrotechnic composition containing naphthalene as the additive. Also, with increasing particle size, the number of carbon atoms available to be burnt decreased owing to which the ignition delay time was observed to be lesser in pyrotechnic stars having naphthalene of larger particle size as the additive. 
Combustion of naphthalene produces a significant amount of soot at around the temperature of $220^{\circ} \mathrm{C}$ (Sobhy et al. 2009). It is advocated that these produced soot particles acted as hot points, transferring additional heat energy to the pyrotechnic charge while serving as an additional heat source.

Activated carbon had been observed to act as a catalyst for the reaction between the fuel (shellac and carbon) and the oxidizer (Verma and Ramakrishna 2010). The diffused oxygen present in the activated carbon started the ignition of the pyrotechnic star with reduced ignition delay time as the fuel had oxygen available before the production of free oxygen achieved through the decomposition of potassium nitrate. Also, carbon presented in its raw form in activated carbon is the most easily igniting form that further acted as an enhancer in the composition's combustion.

Figures $4 \mathrm{a}$ and $4 \mathrm{~b}$ comprehensively represent the per cent reductions achieved in the ignition delay time for various compositions having $3 \%$ and $5 \%$ additive incorporated in the composition, respectively. It was observed that for both of the compositions where naphthalene (particle size $<75 \mu \mathrm{m}$ ) was added as $3 \%$ and $5 \% \mathrm{wt} . \%$, delivered a reduction in ignition delay time below $20 \%$.

(a)

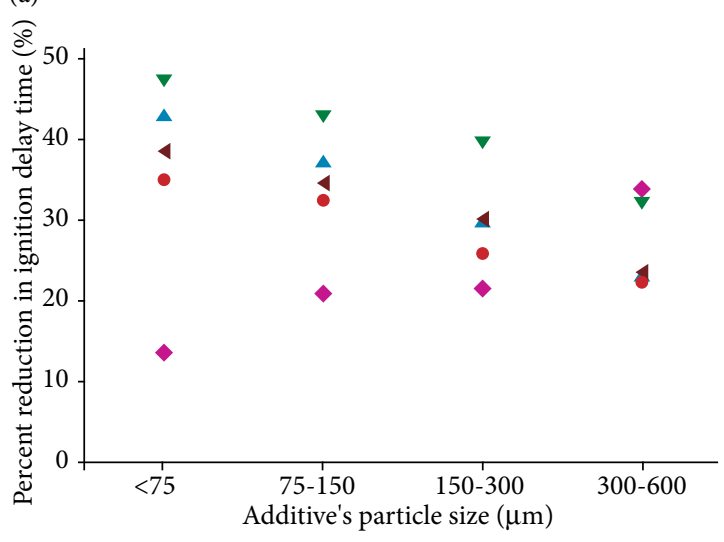

(b)

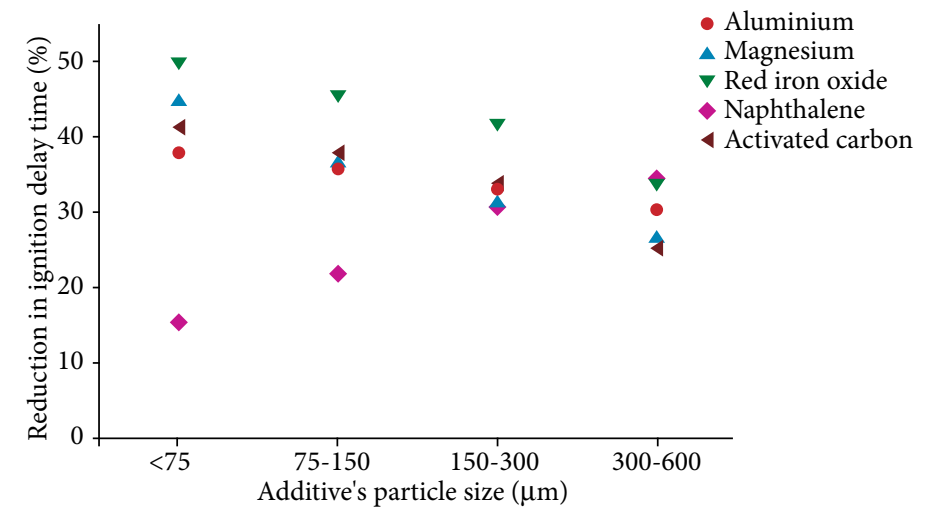

Figure 4. Reduction in ignition delay time (a) $3 \%$, and (b) $5 \%$.

Out of the total 20 compositions having 3\% of the additive's wt.\%, 7 compositions delivered the reduction in ignition delay time between 20-29.99\%, 9 compositions delivered between 30-39.99\%, and 3 compositions delivered between 40-49.99\% when compared to the ignition delay time of base composition. For the 20 compositions with additive's wt.\% as 5\%, 3 compositions delivered the reduction in ignition delay time between 20-29.99\%, 11 compositions delivered between 30-39.99\%, and 5 compositions delivered between 40-49.99\% when compared to the ignition delay time of base composition. From the comparison between the ranges of per cent reductions achieved for 3\% and 5\% of the additive's wt. $\%$, it is evident that an increase in wt. $\%$ of the additives increased the combustion performance of the compositions and more number of compositions tend to provide better decrements in ignition delay times. It can be established that for achieving the per cent reduction between 40-49.99\%, one can utilize 5 different compositions with additive's wt. $\%$ as $5 \%$ as compared to only 3 different compositions with additive's wt. $\%$ as $3 \%$. The actual compositions delivering the required reduction in the ignition delay times may be obtained from Figs. $4 \mathrm{a}$ and $4 \mathrm{~b}$.

From Fig. $4 \mathrm{a}$, it can be observed that when red iron oxide of particle size $<75 \mu \mathrm{m}$ was added as $3 \%$ of the composition weight, an improvement of $47.55 \%$ in the ignition delay time was achieved. This is the maximum reduction in the ignition delay time delivered by any of the compositions with $3 \%$ of additive's wt. $\%$. When $5 \%$ of the red iron oxide of particle size $<75 \mu \mathrm{m}$ was added, the per cent reduction in the ignition delay time was found to be $49.8 \%$ which is the maximum reduction delivered by any of the compositions. Only $13.78 \%$ of reduction in ignition delay time was observed when $3 \%$ of naphthalene having a particle size of $<75 \mu \mathrm{m}$ was added in the composition which is the minimum amongst all of the 40 compositions. It is suggested from the outcomes of the study that except for naphthalene, the investigated metallic and inorganic additives can be used in the pyrotechnic igniter composition to obtain significant decreases in the ignition delay times. Even the same additive with decreasing particle size delivers decreasing magnitudes of ignition delay times. Based on the obtained results, it is recommended that the addition of $5 \%$ of red iron oxide having a particle size of $<75 \mu \mathrm{m}$ can reduce the ignition delay time of the composition by half. activated carbon also delivered 
promising results and can be safely used as an additive in pyrotechnic igniter compositions. The use of naphthalene as an additive can be avoided since it is not observed to deliver desired performance characteristics as compared to other investigated additives.

Correlation between the particle size and ignition delay time represents the strength of the linear relationship between these two quantitative variables. Eq. 5 represents the general formula used to obtain the correlation between the parameters of interest of this study.

$$
\operatorname{Correl}(X, Y)=\frac{\Sigma\left(x_{i}-\bar{x}\right)\left(y_{i}-\bar{y}\right)}{\sqrt{\Sigma\left(x_{i}-\bar{x}\right) \Sigma\left(y_{i}-\bar{y}\right)}}
$$

where, $x_{i}$ and $y_{i}$ represent the values of the $\mathrm{x}$-variable and $\mathrm{y}$-variable whereas $\bar{x}$ and $\bar{y}$ represent the mean of the values of the $\mathrm{x}$-variable and $\mathrm{y}$-variable, respectively.

A strong correlation behaviour was observed between the ignition delay time and the particle sizes of the additives since the magnitude of correlation observed was greater than 0.7 for all of the compositions. Table 4 shows that all of the additives except naphthalene exhibited a similar correlation of direct proportionality between particle size and ignition delay time of the compositions. This concludes that the ignition time delay will tend to decrease with decreasing particle size. Naphthalene too showed a strong correlation, but of inverse proportionality between the parameters of interest. This suggests that the ignition delay time for naphthalene based compositions will tend to increase as the particle size of naphthalene is reduced. Information represented in Table 4 can be used by researchers to obtain, compare and/or study the pattern of change in ignition delay time for different particle sizes than used in the present study.

Table 4. Correlation between ignition delay time and particles size of the additive.

\begin{tabular}{|c|c|c|}
\hline \multirow{2}{*}{ Additive } & \multicolumn{2}{|c|}{ Correlation } \\
\cline { 2 - 3 } & 3\% Additive & 5\% Additive \\
\hline Aluminium & 0.997 & 0.977 \\
\hline Magnesium & 0.966 & 0.912 \\
\hline Activated carbon & 0.990 & 0.998 \\
\hline Red iron oxide & 0.985 & 0.982 \\
\hline Naphthalene & -0.921 & -0.935 \\
\hline
\end{tabular}

\section{CONCLUSION}

The ignition delay time is one of the most important parameters of combustion characteristics of rocket propellant. Different additives of varying particle sizes, when added to the base composition in different wt.\%, achieved significant modifications in the ignition delay time of the pyrotechnic stars. It was observed that the addition of different additives reduced the ignition delay time of shellac and potassium nitrate-based pyrotechnic igniter by a maximum of $49.8 \%$ while the minimum reduction was around $13.78 \%$. Maximum reduction in ignition delay time was achieved when red iron oxide with a particle size of $<75 \mu \mathrm{m}$ was added as $5 \%$ of the composition's weight. Minimum reduction in ignition delay time was observed when naphthalene with a particle size of $<75 \mu \mathrm{m}$ was added as $3 \%$ of the composition's weight. It can be concluded that there is a strong positive correlation i.e. above $90 \%$ between the particle size of additives and reduction in ignition delay time except for naphthalene which showed a strong negative correlation between the investigated parameters. 


\section{AUTHOR'S CONTRIBUTION}

Conceptualization: Bharti MK and Jindal P; Methodology: Bansal L, Jindal P and Bharti MK; Investigation: Bansal L; Writing Original Draft: Bansal L; Writing - Review \& Editing: Bharti MK, Bansal L and Jindal P; Resources: Bharti MK and Jindal P; Supervision: Bharti MK and Jindal P.

\section{ACKNOWLEDGMENTS}

Editors and authors are thankful to Fundação Conrado Wessel for providing the financial support for publishing this article.

\section{REFERENCES}

Aswin C, Vishnu DS, Aravind SK, Deepthi S, Kumaresh K, Arun M, Sanal VRK (2012) Studies on ignition delay and flame spread in high-performance solid rocket motors. Applied Mechanics and Materials 232:316-321. https://doi.org/10.4028/www.scientific.net/ AMM.232.316

Ahmad SR, Russell DA (2005) Laser Ignition of Pyrotechnics - Effects of Wavelength, Composition and Confinement. Propellants, Explosives, Pyrotechnics 30(2):131-139. https://doi.org/10.1002/prep.200400095

Balcarczyk L, inventor; Austriaan Study Society; assignee. 1973 August 7. Rocket with thermal control for influencng the weather. United States patent US 3,750,576.

Barišin D, Batinić-Haberle I (1994) The influence of the various types of binder on the burning characteristics of the magnesium-, boron-, and aluminium-based igniters. Propellants, Explosives, Pyrotechnics 19(3):127-132. https://doi.org/10.1002/prep.19940190304

Bhingarkar V, Singh H (2006) Influence of Cellulosic Binders on Sensitivity and Combustion Behaviour of B-KNO3 Ignition System. Defence Science Journal 56(3):345-351. https://doi.org/10.14429/dsj.56.1898

Chakravarthy SR, Price EW, Sigman RK (1997) Mechanism of burning rate enhancement of composite solid propellants by ferric oxide. Journal of Propulsion and Power 13(4):471-480. https://doi.org/10.2514/2.5208

Danali SM, Palaiah RS, Raha KC (2010) Developments in pyrotechnics. Defence Science Journal 60(2):152-158. https://doi. org/10.14429/dsj.60.333

Devener BV, Anderson SA (2006) Breakdown and Combustion of JP-10 Fuel Catalyzed by Nanoparticulate $\mathrm{CeO}_{2}$ and Fe $\mathrm{O}_{3}$. Energy \& Fuels 20:1886-1894. https://doi.org/10.1021/ef060064g

Feng, Y. C., Xia, Z. X., Huang, L. Y., Ma, L. K., \& Yang, D. L. (2019). Experimental investigation on the ignition and combustion characteristics of a single magnesium particle in air. Combustion, Explosion and Shock Waves, 55(2), 210-219. https://doi. org/10.1134/S0010508219020102

García T, Solsona B, Taylor SH (2006) Naphthalene total oxidation over metal oxide catalysts. Applied Catalysis B: Environmental 66(12):92-99. https://doi.org/10.1016/j.apcatb.2006.03.003

Glotov OG, Surodin GS (2019) Combustion of aluminium and boron agglomerates free falling in air. II. Experimental results. Combustion, Explosion, and Shock Waves 55(3):345-352. https://doi.org/10.1134/S0010508219030122

Gong X, Guo Z, Wang Z (2010) Reactivity of pulverized coals during combustion catalyzed by CeO2 and Fe203. Combust Flame; 157:351-356. https://doi.org/10.1016/j.combustflame.2009.06.025

Hohmann C, Tipton B (2000) Propellant for the NASA standard initiator. NASA/TP-2000-210186.

Hunt ES, inventor; Lovell JT, assignee. 1879 July 15. Improvement in pyrotechnic cartridges. United States patent US 217,534.

Klingenberg G (1984) Experimental study on the performance of pyrotechnic igniters. Propellants, Explosives, Pyrotechnics 9(3):91-107. https://doi.org/10.1002/prep.19840090304

Kulkarni AK, Kumar M, Kuo KK (1980) Review of solid propellant ignition studies. AlAA journal, 20(2): 243-244. https://doi. org/10.2514/3.51071

Li LB, Chen X, Musa O, Zhou CS, Zhu M (2018) The effect of pressure and oxygen concentration on the ignition and combustion of aluminium- 
magnesium fuel-rich propellant. Aerospace Science and Technology 76:394-401. https://doi.org/10.1016/j.ast.2017.12.032

Mattisson T, Lyngfelt A, Cho $\mathrm{P}$ (2001) The use of iron oxide as an oxygen carrier in chemical-looping combustion of methane with inherent separation of $\mathrm{CO}_{2}$. Fuel 80(13):1953-1962. https://doi.org/10.1016/S0016-2361(01)00051-5

Quintiere JG (2006) Fundamentals of fire phenomena. West Sussex (England): John Wiley \& Sons, Ltd. https://doi. org/10.1002/0470091150

Shafirovich EY, Goldshleger UI (1991) Combustion of magnesium particles in $\mathrm{CO}_{2} / \mathrm{CO}$ mixtures. Combustion Science and Technology 84(1-6):33-43. https://doi.org/10.1080/00102209208951843

Sharma SK, Shukla SK, Vaid DN (1983) Shellac - structure, characteristics \& modification. Defence Science Journal 33(3):261-271. https://doi.org/10.14429/dsj.33.6181

Singh H, Somayajulu MR, Rao RB (1988) Selection of an igniter system for magnesium-based solid fuel rich propellant. Propellants, Explosives, Pyrotechnics 13(2):52-54. https://doi.org/10.1002/prep.19880130205

Sivan J, Haas Y (2015) Laser ignition of various pyrotechnic mixtures - An experimental study. Propellants, Explosives, Pyrotechnics 40(5):755-758. https://doi.org/10.1002/prep.201500080

Sobhy A, Guthrie RIL, Butler LS, Kozinski JA (2009) Naphthalene combustion in supercritical water flames. Proceedings of the Combustion Institute 32(2):3231-3238. https://doi.org/10.1016/j.proci.2008.06.173

Tewarson A (2002) Generation of heat and chemical compounds in fires. SFPE Hand-book of Fire Protection Engineering, Third edition. National Fire Protection Association, Section 3:82-162.

Verma S, Ramakrishna PA (2010) Activated charcoal - A novel burn rate enhancer of aluminized composite propellants. Combustion and Flame 157(6):1202-10. https://doi.org/10.1016/j.combustflame.2009.11.017

Ye M, Zhang S, Liu S, Han A \& Chen X (2016) Preparation and Characterization of Pyrotechnics Binder-Coated Nano-Aluminium Composite Particles. Journal of Energetic Materials 35(3):300-313. https://doi.org/10.1080/07370652.2016.1186252 